\title{
Outcome and performance of bioprosthetic pulmonary valve replacement in patients with congenital heart disease
}

\author{
Rio Nomoto, BA, ${ }^{\mathrm{a}, \mathrm{c}}$ Lynn A. Sleeper, ScD, ${ }^{\mathrm{b}}$ Michele J. Borisuk, MSN, CPNP, ${ }^{\mathrm{c}}$ Lisa Bergerson, MD, MPH, \\ Frank A. Pigula, MD, ${ }^{\mathrm{c}}$ Sitaram Emani, MD, ${ }^{\mathrm{c}}$ Francis Fynn-Thompson, MD, ${ }^{\mathrm{c}}$ John E. Mayer, MD, \\ Pedro J. del Nido, $\mathrm{MD},{ }^{\mathrm{c}}$ and Christopher W. Baird, $\mathrm{MD}^{\mathrm{c}}$
}

\section{ABSTRACT}

Objectives: The goal of this single-center series was to assess differences in reintervention by the type of valve used for surgical bioprosthetic pulmonary valve replacement and to identify independent predictors of reintervention.

Methods: Data were retrospectively collected for 611 patients undergoing pulmonary valve replacement from 1996 to 2014. Kaplan-Meier estimation and Cox proportional hazards regression methodologies were used.

Results: The median age of patients was 17.8 years (interquartile range, 11.9-27.3). The diagnosis was tetralogy of Fallot in $69 \%$ of patients. The median follow-up was 3.0 years (interquartile range, 1.1-5.3). Valve types included Sorin Mitroflow (Milan, Italy), 316 (50\%; median age 16.5 years); Carpentier-Edwards (Irvine, Calif) Magna/MagnaEase, 223 (35\%; median age, 19.3 years); and Carpentier-Edwards Perimount, 72 (11\%; median age, 21.9 years). Reintervention occurred in $6.7 \%$ of patients (41/633) and was higher in children than adults (hazard ratio, 4.8). Age-adjusted 5-year reintervention rates were Sorin Mitroflow, 13.4\%; Carpentier-Edwards Magna/MagnaEase, 2.1\%; and Carpentier-Edwards Perimount, $0 \%$. Reintervention was not associated with gender, valve insertion method, or concurrent procedures. The only independent risk factor for reintervention after controlling for age was valve type $(P<.001)$. The Sorin Mitroflow valve had a shorter time to reintervention than the other 2 valve types (hazard ratios both $>7$, each $P<.001)$. Differences by valve type did not depend on age (interaction $P=.61$ ).

Conclusions: Bioprosthetic pulmonary valve replacement in patients with congenital heart disease has excellent short-term outcomes, but children have an approximately 5-fold greater risk of reintervention than adults. Independently of age, reintervention rates vary by valve type. These differences may be important in valve selection and follow-up. ( $\mathrm{J}$ Thorac Cardiovasc Surg 2016;152:1333-42)

Survival of children with congenital heart disease (CHD) has improved significantly over the last 15 years with advances in surgical techniques and perioperative care, leading to more adults with CHD than children. As a result, there is an increasing number of adolescents and adults

From the ${ }^{\mathrm{a}}$ Tufts Medical School; and Departments of ${ }^{\mathrm{b}}$ Cardiology and ${ }^{\mathrm{c}}$ Cardiac Surgery, Boston Children's Hospital and Harvard Medical School, Boston, Mass.

Read at the 95th Annual Meeting of The American Association for Thoracic Surgery, Seattle, Washington, April 25-29, 2015.

Received for publication May 1, 2015; revisions received June 23, 2016; accepted for publication June 25, 2016; available ahead of print Sept 13, 2016.

Address for reprints: Christopher W. Baird, MD, Department of Cardiac Surgery, Boston Children's Hospital and Harvard Medical School, 300 Longwood Ave, 612 Farley, Boston, MA 02115 (E-mail: bairdc1@gmail.com). $0022-5223 / \$ 36.00$

Copyright (c) 2016 Published by Elsevier Inc. on behalf of The American Association for Thoracic Surgery

http://dx.doi.org/10.1016/j.jtcvs.2016.06.064

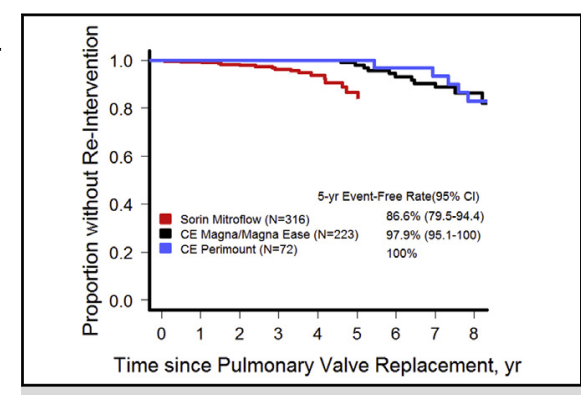

Age-adjusted freedom from reintervention by valve type.

\section{Central Message}

Reintervention rates after bioprosthetic PVR vary by age and valve type, affecting valve choice and follow-up.

\section{Perspective}

Longer-term outcomes and optimal valve type for PVR in the pediatric population are unknown. All measures related to younger patient age at surgery were risk factors for reintervention. The association of age at surgery with time to reintervention was independent of valve type. The Sorin Mitroflow valve (Milan, Italy) was a significant age-adjusted risk factor for reintervention relative to the other valve types.

See Editorial page 1230. undergoing pulmonary valve replacement (PVR) procedures. Current indications for PVR include asymptomatic and symptomatic patients with increased risk for right ventricular dilation and dysfunction, exercise intolerance, arrhythmia, and sudden cardiac events. Patients with tetralogy of Fallot (TOF) frequently develop severe pulmonary regurgitation after initial right ventricular outflow tract (RVOT) repair, and placement of bioprosthetic valves has demonstrated significant improvements in right ventricle

Scanning this QR code will take you to the supplemental figure and tables for this article. To view the AATS 2015 Webcast, see the $\mathrm{URL}$ at the end of the article.

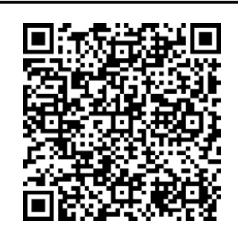




$$
\begin{aligned}
\text { Abbreviations and Acronyms } \\
\text { BMI }=\text { body mass index } \\
\text { BSA }=\text { body surface area } \\
\text { CE }=\text { Carpentier-Edwards } \\
\text { CHD }=\text { congenital heart disease } \\
\text { CI }=\text { confidence interval } \\
\text { HR }=\text { hazard ratio } \\
\text { MRI }=\text { magnetic resonance imaging } \\
\text { PVR }=\text { pulmonary valve replacement } \\
\text { RV }=\text { right ventricle } \\
\text { RVOT }=\text { right ventricular outflow tract } \\
\text { TOF }=\text { tetralogy of Fallot }
\end{aligned}
$$

(RV) function and exercise tolerance in these patients. ${ }^{1,2}$ Bovine pericardial bioprosthetic valves in the aortic position in adults have demonstrated excellent short- and mid-term results, but many fail long term because of calcification resulting in increased leaflet rigidity. ${ }^{3}$ However, longer-term outcomes and optimal valve type for PVR in the pediatric population are unknown. Our objective was to compare reintervention rates among different bioprosthetic valve types in patients with CHD undergoing PVR and to determine whether additional independent risk factors exist.

\section{MATERIALS AND METHODS}

This was an institutional review board-approved retrospective review of all patients with CHD who underwent bioprosthetic PVR at Boston Children's Hospital between January 1, 1996, and February 28, 2014. The data of 611 patients undergoing bioprosthetic PVR at Children's Hospital Boston were included. The primary end point was reintervention on the pulmonary valve and defined as a surgical procedure for valve replacement or a cardiac catheterization intervention for valve replacement (for insertion of a Melody [Medtronic Inc, Minneapolis, Minn] bovine jugular valve).

Demographics collected include date of birth, sex, intraoperative height, weight, and body surface area (BSA). Patient history includes the patient's primary diagnosis, and previous interventions including PVR(s), Ross procedure, internal cardiac defibrillator, pacemaker, catheterization, most recent type of RVOT, and relevant procedures. Surgical data were obtained from operative notes. Variables of interest include the date of admission, date of PVR procedure, indication for PVR, date of discharge, morbidity, and any complications before discharge. In addition, the specific valve type, valve size, valve insertion methods, and concomitant procedures were recorded.

The last date of follow-up record included in this study was July 30 , 2014. Follow-up includes date of most recent follow-up, echocardiogram reports, and magnetic resonance image reports obtained as part of a routine examination. More specifically, data from echocardiogram reports will include the date of echocardiogram, estimated RV pressure gradient, maximum RVOT pressure gradient, and degree of pulmonary stenosis, pulmonary regurgitation, tricuspid regurgitation, RV dysfunction, and left ventricular dysfunction.

\section{Definitions}

BSA was calculated using the Haycock formula: $0.024265 \times$ weight $^{0.5378} \times$ height $^{0.3964}$. When height was not available, BSA was calculated from weight only: $0.1 *\left(\right.$ weight $\left.^{0.6667}\right)$. Weight-for-age and body mass index (BMI)-for-age $z$ scores and percentiles were calculated for the 371 patients aged less than 20 years using the Centers for Disease Control reference standard. A $z$ score represents the number of standard deviation units the measurement is away from the mean of a healthy individual (mean $z$ score of zero). Valve internal diameter dimensions were directly measured, and valve orifice area was calculated as the valve circumference: $3.14159 \times(0.5 \times$ measured internal diameter $){ }^{2}$

\section{Statistical Methods}

We compared patient characteristics by valve type using the chi-square test for categoric variables, analysis of variance for continuous variables with symmetric distributions, and Kruskal-Wallis test for other variables. Descriptive statistics used were frequency and percentage for categoric variables, mean \pm standard deviation, and median with interquartile range for continuous variables. Dichotomous weight and BMI $z$ scores were created to assess very small body size relative to age $(z$ score $<-2)$ and larger body size relative to age $(z$ score $>1)$.

Kaplan-Meier methodology and the log-rank test were used to estimate time to reintervention and compare unadjusted reintervention rates. Follow-up time was censored at the latest known follow-up or death. Cox proportional hazards regression was used to estimate covariateadjusted associations between time to reintervention and valve type.

Candidate predictors for multivariable Cox proportional hazards regression with a stepwise selection procedure included labeled valve size, valve orifice area, weight, BSA, native RV outflow tract, and concurrent surgical procedure variables that had a univariate $P$ value less than .20 . Age at surgery and valve type were fixed in the multivariable model before applying the selection procedure. The criterion for entry of other variables into the multivariable model was $P<.15$, and the criterion to remain in the model was $P<.05$. The selected model was then refined as needed to account for differences in the complete-case dataset and the maximum sample size dataset.

Estimates of age-adjusted freedom from reintervention by valve type were obtained by the method of direct adjustment, fitting a stratified Cox proportional hazards model with a differing baseline hazard for each valve type and averaging the event-free probability estimates across all observations (of varying ages) at a given follow-up time. The estimates and confidence intervals (CIs) were calculated in SAS (SAS Institute, Inc, Cary, NC) using the method of Zhang and colleagues. ${ }^{4}$ Analyses were performed using SAS version 9.4 and $\mathrm{R}$ version 3.2.1.

\section{RESULTS \\ Patient Characteristics}

Patient characteristics by valve type are shown in Table 1. Of the 611 patients who underwent bioprosthetic PVR between 1996 and 2014 (Figure E1), the valve type used was the Sorin Mitroflow (Milan, Italy) (LXA nontreated), 316 (50\%); the Carpentier-Edwards (CE) (Irvine, Calif) Magna or MagnaEase, 223 (35\%); and the CE Perimount, $72(11 \%)$. The median age at surgery was 17.8 years (interquartile range, $11.9-27.3$ years), and $50 \%$ of patients were aged less than 18 years $(P<.001$ across valve types). Only 8 patients were infants, and none were neonates. Patients receiving a Sorin Mitroflow were younger (median, 16.5 years) than those who received the CE Magna/MagnaEase (19.3 years) and CE Perimount valves (21.9 years).

The Sorin Mitroflow valves were implanted in patients in 2008 or later, in contrast to CE Perimount valves that were mostly all implanted in patients before 2006. Pulmonary 
TABLE 1. Baseline patient characteristics overall and by valve type

\begin{tabular}{|c|c|c|c|c|c|}
\hline Variable & $\begin{array}{c}\text { Overall } \\
(\mathrm{N}=611)\end{array}$ & $\begin{array}{c}\text { Sorin Mitroflow } \\
\text { (Milan, Italy) } \\
(\mathbf{N}=\mathbf{3 1 6}) \\
\end{array}$ & $\begin{array}{c}\text { CE (Irvine, Calif) } \\
\text { Magna/Magna Ease } \\
(\mathbf{N}=\mathbf{2 2 3}) \\
\end{array}$ & $\begin{array}{c}\text { CE } \\
\text { Perimount } \\
(\mathbf{N}=72) \\
\end{array}$ & $P$ value \\
\hline \multicolumn{6}{|l|}{ Type of pulmonary valve } \\
\hline Sorin Mitroflow & $316(51.7 \%)$ & 316 & & & \\
\hline CE Magna & $176(28.8 \%)$ & & 176 & & \\
\hline CE Magna-Ease & $41(6.7 \%)$ & & 41 & & \\
\hline CE Pericardial (model unknown) & $6(1.0 \%)$ & & 6 & & \\
\hline CE Perimount bovine & $72(11.8 \%)$ & & & 72 & \\
\hline \multicolumn{6}{|l|}{ Age at primary surgery, $y$} \\
\hline Mean \pm SD & $21.1 \pm 13.7$ & $18.6 \pm 12.7$ & $23.4 \pm 14.4$ & $25.0 \pm 13.8$ & $<.001$ \\
\hline Median (IQR) & $17.8(11.9-27.3)$ & $16.5(9.8-22.7)$ & $19.3(13.3-31.0)$ & $21.9(14.6-32.5)$ & .003 \\
\hline Age $<18.0$ y at primary surgery & $307(50.2 \%)$ & $180(47.0 \%)$ & $100(44.8 \%)$ & $27(37.5 \%)$ & .002 \\
\hline Age group (primary surgery), y & & & & & $<.001$ \\
\hline$<6$ & $66(9.2 \%)$ & $39(12.3 \%)$ & $15(6.7 \%)$ & $2(2.8 \%)$ & \\
\hline $6-<12$ & $98(16.0 \%)$ & $63(19.9 \%)$ & $26(11.7 \%)$ & $9(12.5 \%)$ & \\
\hline $12-<18$ & $153(25.0 \%)$ & $78(24.7 \%)$ & $59(26.5 \%)$ & $16(22.2 \%)$ & \\
\hline $18-<27$ & $148(24.2 \%)$ & $79(25.0 \%)$ & $51(22.9 \%)$ & $18(25.0 \%)$ & \\
\hline$\geq 27$ & $156(25.5 \%)$ & $57(18.0 \%)$ & $72(32.3 \%)$ & $27(37.5 \%)$ & \\
\hline Male & $367(60.1 \%)$ & $182(57.6 \%)$ & $142(63.7 \%)$ & $43(59.7 \%)$ & .36 \\
\hline Weight at primary surgery, $\mathrm{kg}$ & $55.8 \pm 25.9$ & $52.3 \pm 26.2$ & $60.6 \pm 26.3$ & $56.3 \pm 20.6$ & .001 \\
\hline Weight-for age $z$ score (if $<20$ y) $(\mathrm{n}=353)$ & $-0.4 \pm 1.4$ & $-0.4 \pm 1.3$ & $-0.3 \pm 1.3$ & $-0.7 \pm 1.7$ & .43 \\
\hline Weight-for-age $z$ score $<-2$ & $41(11.6 \%)$ & $25(12.3 \%)$ & $11(9.4 \%)$ & $5(15.2 \%)$ & .59 \\
\hline Weight-for-age $z$ score $>1$ & $52(14.7 \%)$ & $28(13.8 \%)$ & $19(16.2 \%)$ & $5(15.2 \%)$ & .84 \\
\hline $\mathrm{BSA}, \mathrm{m}^{2}$ & $1.5 \pm 0.5$ & $1.5 \pm 0.5$ & $1.6 \pm 0.5$ & $1.5 \pm 0.4$ & $<.001$ \\
\hline BMI, $\mathrm{kg} / \mathrm{m}^{2}(\mathrm{n}=578)$ & $22.4 \pm 6.3$ & $21.8 \pm 6.2$ & $23.1 \pm 6.6$ & $22.6 \pm 5.3$ & .06 \\
\hline BMI-for-age $z$ score (if $<20$ y) $(\mathrm{n}=328)$ & $-0.1 \pm 1.3$ & $-0.1 \pm 1.4$ & $-0.2 \pm 1.3$ & $-0.1 \pm 1.4$ & .95 \\
\hline BMI-for-age $z$ score $<-2$ & $23(7.0 \%)$ & $14(7.5 \%)$ & $6(5.4 \%)$ & $3(10.7 \%)$ & .57 \\
\hline BMI-for-age $z$ score $>1$ & $68(20.7 \%)$ & $39(20.7 \%)$ & $23(20.5 \%)$ & $6(21.4 \%)$ & .99 \\
\hline Year of surgery & & & & & $<.001$ \\
\hline Before 2006 & $143(23.4 \%)$ & 0 & $74(33.2 \%)$ & $69(95.8 \%)$ & \\
\hline 2006 or later & $468(76.6 \%)$ & $316(100 \%)$ & $149(66.8 \%)$ & $3(4.2 \%)$ & \\
\hline \multicolumn{6}{|c|}{ Surgical indication for PVR (not mutually exclusive) } \\
\hline Pulmonary regurgitation & $478(78.2 \%)$ & $255(80.7 \%)$ & $170(76.2 \%)$ & $53(73.6 \%)$ & .28 \\
\hline Pulmonary stenosis & $120(19.6 \%)$ & $85(26.9 \%)$ & $26(11.7 \%)$ & $9(12.5 \%)$ & $<.001$ \\
\hline Endocarditis & $4(0.7 \%)$ & $3(1.0 \%)$ & $0(0.0 \%)$ & $1(1.4 \%)$ & .29 \\
\hline Other & $44(7.2 \%)$ & $22(7.0 \%)$ & $17(7.6 \%)$ & $5(6.9 \%)$ & .95 \\
\hline Native outflow tract used $(n=600)$ & $481(80.2 \%)$ & $239(76.4 \%)$ & $181(83.0 \%)$ & $61(88.4 \%)$ & .03 \\
\hline Type of outflow tract $(n=606)$ & & & & & .09 \\
\hline Native & $53(8.7 \%)$ & $18(5.7 \%)$ & $25(11.4 \%)$ & $10(14.5 \%)$ & \\
\hline Augmented RVOT/transannular patch & $423(69.8 \%)$ & $218(69.2 \%)$ & $155(70.8 \%)$ & $50(72.5 \%)$ & \\
\hline Homograft & $91(15.0 \%)$ & $60(19.0 \%)$ & $26(11.9 \%)$ & $5(7.2 \%)$ & \\
\hline Valved tube & $14(2.3 \%)$ & $8(2.5 \%)$ & $5(2.3 \%)$ & $1(1.4 \%)$ & \\
\hline Nonvalved tube & $14(2.3 \%)$ & $6(1.9 \%)$ & $6(2.7 \%)$ & $2(2.9 \%)$ & \\
\hline Other & $11(1.8 \%)$ & $5(1.6 \%)$ & $2(0.9 \%)$ & $1(1.4 \%)$ & \\
\hline Insertion method $(\mathrm{n}=608)$ & & & & & .005 \\
\hline Isolated PVR & $83(13.7 \%)$ & $31(9.8 \%)$ & $40(18.2 \%)$ & $12(16.7 \%)$ & \\
\hline PVR with anterior patch & $444(73.0 \%)$ & $231(73.1 \%)$ & $156(70.9 \%)$ & $57(79.2 \%)$ & \\
\hline PV with tube & $80(13.2 \%)$ & $54(17.1 \%)$ & $23(10.5 \%)$ & $3(4.2 \%)$ & \\
\hline Other & $1(0.2 \%)$ & 0 & $1(0.5 \%)$ & 0 & \\
\hline \multicolumn{6}{|l|}{ Valve size } \\
\hline Labeled valve size, $\mathrm{mm}$ & $25.0 \pm 2.6$ & $24.3 \pm 2.5$ & $25.6 \pm 2.4$ & $25.9 \pm 2.4$ & $<.001$ \\
\hline Internal diameter valve size, $\mathrm{mm}$ & $22.5 \pm 3.2$ & $20.3 \pm 2.3$ & $24.6 \pm 2.4$ & $24.9 \pm 2.4$ & $<.001$ \\
\hline Valve orifice area, $\mathrm{mm}^{2}$ & $404 \pm 112$ & $330 \pm 71$ & $481 \pm 91$ & $490 \pm 89$ & $<.001$ \\
\hline Valve orifice area/BSA, $\mathrm{mm}^{2} / \mathrm{m}^{2}$ & $287 \pm 97$ & $249 \pm 75$ & $322 \pm 98$ & $342 \pm 112$ & $<.001$ \\
\hline
\end{tabular}


TABLE 1. Continued

\begin{tabular}{|c|c|c|c|c|c|}
\hline Variable & $\begin{array}{c}\text { Overall } \\
(\mathrm{N}=611)\end{array}$ & $\begin{array}{c}\text { Sorin Mitroflow } \\
\text { (Milan, Italy) } \\
(\mathbf{N}=\mathbf{3 1 6}) \\
\end{array}$ & $\begin{array}{c}\text { CE (Irvine, Calif) } \\
\text { Magna/Magna Ease } \\
(\mathbf{N}=\mathbf{2 2 3}) \\
\end{array}$ & $\begin{array}{c}\text { CE } \\
\text { Perimount } \\
(\mathbf{N}=72) \\
\end{array}$ & $P$ value \\
\hline \multicolumn{6}{|l|}{ Diagnosis } \\
\hline TOF & $419(68.6 \%)$ & $214(67.7 \%)$ & $154(69.1 \%)$ & $51(70.8 \%)$ & .86 \\
\hline Complete atrioventricular canal defect & $12(2.0 \%)$ & $7(2.2 \%)$ & $3(1.3 \%)$ & $2(2.8 \%)$ & .67 \\
\hline Pulmonary stenosis diagnosis, no TOF & $77(12.6 \%)$ & $38(12.0 \%)$ & $30(13.5 \%)$ & $9(12.5 \%)$ & .89 \\
\hline Pulmonary atresia diagnosis, no TOF & $45(7.4 \%)$ & $27(8.5 \%)$ & $16(7.2 \%)$ & $2(2.8 \%)$ & .24 \\
\hline \multicolumn{6}{|l|}{ Procedures concurrent with primary surgery } \\
\hline Any surgical procedure & $292(47.8 \%)$ & $156(49.4 \%)$ & $99(44.4 \%)$ & $37(51.4 \%)$ & .42 \\
\hline Left pulmonary arterioplasty & $65(10.6 \%)$ & $33(10.4 \%)$ & $26(11.7 \%)$ & $6(8.3 \%)$ & .72 \\
\hline Left, right, or main pulmonary arterioplasty & $101(16.5 \%)$ & $58(18.4 \%)$ & $35(15.7 \%)$ & $8(11.1 \%)$ & .30 \\
\hline Tricuspid valve procedure & $121(19.8 \%)$ & $66(20.9 \%)$ & $38(17.0 \%)$ & $17(23.6 \%)$ & .37 \\
\hline $\mathrm{RV}$ resection/plication & $34(5.6 \%)$ & $18(5.7 \%)$ & $10(4.5 \%)$ & $6(8.3 \%)$ & .46 \\
\hline Aortic valve procedure & $20(3.3 \%)$ & $15(4.7 \%)$ & $4(1.8 \%)$ & $1(1.4 \%)$ & .10 \\
\hline Pacemaker & $20(3.3 \%)$ & $9(2.8 \%)$ & $9(4.0 \%)$ & $2(2.8 \%)$ & .72 \\
\hline
\end{tabular}

$C E$, Carpentier-Edwards; $S D$, standard deviation; $I Q R$, interquartile range; $B S A$, body surface area; $B M I$, body mass index; $P V R$, pulmonary valve replacement; $R V O T$, right ventricular outflow tract; $P V$, pulmonary valve; $T O F$, tetralogy of Fallot; $R V$, right ventricle.

regurgitation was the most common indication for PVR $(78 \%)$ and did not differ by valve type. An indication of pulmonary stenosis was most common for cases with Sorin Mitroflow valves, and its prevalence (27\%) was higher than the prevalence of pulmonary stenosis in patients with the other 2 valve types $(12 \%-13 \% ; P<.001)$. An augmented RVOT or transannular patch was used for the majority of cases $(70 \%$ overall). There were no differences in the distributions of gender (59\% were male) or primary diagnosis across valve types.

\section{Reintervention Rates by Age}

Of the 611 total cases, 41 underwent a surgical $(n=16)$ or cardiac catheterization $(n=25)$ reintervention to replace the pulmonary valve. Time to reintervention differed

A

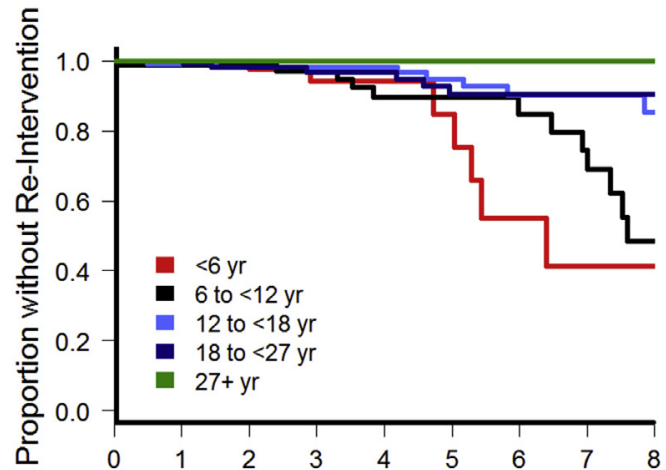

Time since Pulmonary Valve Replacement, yr No. at Risk

$<6 \mathrm{yr} \quad 56$

6 to $<12$ yr $\quad 98$

12 to $<18 \mathrm{yr} \quad 153$

18 to $<27 \mathrm{yr} \quad 148$

$27+\mathrm{yr}$ significantly by age at surgery $(P<.001$; Tables E1 and E2; Figure 1, A). The risk of reintervention was approximately 5 times greater for children than adults (hazard ratio [HR], 54.8; 95\% CI, 2.2-10.6) and decreased by $10 \%$ for each increasing year of age at surgery (HR, 0.90; 95\% CI, 0.86-0.94). Almost all events occurred more than 3 years after the primary surgery, regardless of age. After the first 3 years, the differences by age emerged. The 5-year reintervention rate was $11 \%$ for patients aged less than 12 years, $7 \%$ for patients aged 12 to 27 years, and $0 \%$ for patients aged 27 years or older. Within the cohort aged less than 18 years, ages less than 6 years and 6 to 12 years had statistically similar outcomes (HR, 1.9; 95\% CI, 0.76-4.5), and these groups had a significantly higher reintervention rate than those undergoing PVR at age 12 to 18 years.

FIGURE 1. A, Freedom from reintervention by age at primary surgery, 41 events. Log-rank $P<.001$. Truncated at 8 years. Number of events not shown in each group are 1 in less than 6 years, 1 in 6 to 12 years, 4 in 12 to 18 years, 2 in 18 to 27 years, and 1 in 27 + years. See Table E1 for $95 \%$ confidence limits for $3-, 5-$, and 10 -year event rates. B, Age-adjusted freedom from reintervention by valve type. Cox regression model $P<.001$. Truncated at 8 years. See Table E3 for $95 \%$ confidence limits for 3,5 , and 10 -year event rates. 
TABLE 2. Study outcomes overall and by valve type

\begin{tabular}{|c|c|c|c|c|}
\hline Variable & $\begin{array}{c}\text { Overall } \\
(\mathrm{N}=611)\end{array}$ & $\begin{array}{l}\text { Sorin Mitroflow } \\
\quad(\mathbf{N}=\mathbf{3 1 6})\end{array}$ & $\begin{array}{c}\text { CE Magna/ } \\
\text { Magna Ease } \\
(\mathbf{N}=\mathbf{2 2 3})\end{array}$ & $\begin{array}{c}\text { CE Perimount } \\
(\mathbf{N}=72)\end{array}$ \\
\hline \multicolumn{5}{|l|}{ Follow-up time, $\mathrm{y}$} \\
\hline Mean \pm SD & $3.6 \pm 3.2$ & $2.4 \pm 1.6$ & $4.3 \pm 3.0$ & $6.7 \pm 5.4$ \\
\hline Median (IQR) & $3.0(1.1-5.3)$ & $2.4(1.0-3.7)$ & $4.9(1.2-6.9)$ & $7.8(0.0-10.5)$ \\
\hline Surgical reintervention, no. & 16 & 6 & 6 & 4 \\
\hline $\begin{array}{l}\text { Catheter-based reintervention (Melody } \\
\text { [Medtronic Inc, Minneapolis, Minn] valve } \\
\text { placement), no. }\end{array}$ & 25 & 11 & 7 & 7 \\
\hline $\begin{array}{l}\text { Reintervention (surgical or catheter-based } \\
\text { Melody valve placement), no. }\end{array}$ & 41 & 17 & 13 & 11 \\
\hline Children & $32 / 307$ & $13 / 180$ & $10 / 100$ & $9 / 27$ \\
\hline Adults & $9 / 304$ & $4 / 136$ & $3 / 123$ & $2 / 45$ \\
\hline \multicolumn{5}{|l|}{ Event rates $(95 \% \mathrm{CI})^{*}$} \\
\hline 3-y event rate & $2.2 \%(1.2-4.3)$ & $4.7 \%(2.4-9.0)$ & $0 \%$ & $0 \%$ \\
\hline Children & $2.8 \%(1.3-6.3)$ & $5.3 \%(2.3-11.6)$ & $0 \%$ & $0 \%$ \\
\hline Adults & $1.6 \%(0.5-4.8)$ & $3.9 \%(1.2-12.3)$ & $0 \%$ & $0 \%$ \\
\hline 5-y event rate & $6.3 \%(3.9-10.1)$ & $17.6 \%(9.7-30.5)$ & $1.8 \%(0.4-6.9)$ & $0 \%$ \\
\hline Children & $8.0 \%(4.5-14.1)$ & $22.1 \%(11.4-40.1)$ & $0 \%$ & $0 \%$ \\
\hline Adults & $4.5 \%(2.0-10.1)$ & $9.3 \%(2.7-28.8)$ & $3.3 \%(0.8-12.5)$ & $0 \%$ \\
\hline 10 -y event rate & $24.4 \%(16.6-35.1)$ & - & $23.2 \%(11.7-43.0)$ & $14.6 \%(7.2-31.8)$ \\
\hline Children & $46.0 \%(30.7-64.4)$ & $29.2 \%(15.0-51.9)$ & $44.2 \%(21.1-76.3)$ & $36.7 \%(18.3-64.5)$ \\
\hline Adults & $4.5 \%(2.0-10.1)$ & $9.3 \%(2.7-28.8)$ & $3.3 \%(0.8-12.5)$ & $0 \%$ \\
\hline Death $\dagger$ & $18 / 609(3.0 \%)$ & $2 / 316(0.6 \%)$ & $6 / 222(2.7 \%)$ & $10 / 71(14.1 \%)$ \\
\hline
\end{tabular}

PVR was performed at an older age before 2006 compared with 2006 or later (median, 19.3 vs 17.1 years, $P=.01)$. However, the age-associated risk of reintervention remained even after adjustment for era $(P<.001)$. Furthermore, the association of age at surgery with time to reintervention was independent of valve type (interaction $P=.61$ ).

\section{Reintervention Rates by Valve Type}

Median follow-up time was 3.0 years (interquartile range, 1.1-5.3) and differed by valve type, with a median follow-up of 2.4 years for the Sorin Mitroflow, 4.9 years for the CE Magna/Magna Ease, and 7.8 years for the CE Perimount. The unadjusted 5-year Kaplan-Meier estimated reintervention rates were $18 \%, 2 \%, 0 \%$, and $0 \%$ for the Sorin Mitroflow, Magna/Magna Ease, and CE Perimount valves, respectively. The 3-year reintervention rate for the Sorin Mitroflow was $5 \%(0 \%$ for all other valve types) (Tables 2 and 3$)$.

\section{Other Univariate Risk Factors for Reintervention}

All measures related to younger patient age at surgery were risk factors for reintervention (ie, lower weight, BSA, BMI; $P<.001$ ) (Table E2). Larger labeled valve size (HR, 0.76 per $\mathrm{mm}$ ), internal diameter valve size (HR, 0.73 per $\mathrm{mm}$ ), and valve orifice area (HR, 0.84 per $\left.20 \mathrm{~mm}^{2}\right)$ were protective against reintervention $(P<.001)$. We also hypothesized whether valve orifice area was a predictor for children but not adults, but found no such evidence (interaction $P=.88$ ). Of note, a smaller BSA-adjusted valve orifice area (area divided by BSA) was protective, although less significantly so $(P=.03)$. An additional procedure concurrent with the initial valve replacement and insertion type was not a risk factor for reintervention. A non-native outflow tract was a risk factor, but its use was highly correlated with younger age and was not associated with reintervention in age-adjusted analyses.

\section{Multivariable Model for Time to Reintervention}

A multivariable model to examine covariate-adjusted differences in time to reintervention by valve type was constructed, with age at surgery included in the model to account for the age difference of the cohorts with different valve types (Table 3). After inclusion of age and valve type, no other covariates that applied to all patients were

TABLE 3. Multivariable Cox regression model of time to reintervention $(n=611 ; 41$ events $)$

\begin{tabular}{lccc}
\hline \multicolumn{1}{c}{ Variable } & HR & $\mathbf{9 5} \% \mathbf{C I}$ & $\boldsymbol{P}$ value \\
\hline Age at surgery, y & 0.91 & $(0.87-0.95)$ & $<.001$ \\
Valve type & & & $<.001$ \\
$\quad$ Sorin Mitroflow vs CE Magna/ & 7.16 & $(2.39-21.40)$ & $<.001$ \\
$\quad$ MagnaEase & & & \\
$\quad$ Sorin Mitroflow vs CE Perimount & 11.83 & $(2.89-48.51)$ & $<.001$ \\
$\quad$ CE Magna/MagnaEase vs CE & 1.65 & $(0.57-4.81)$ & .356 \\
$\quad$ Perimount & & & \\
\hline$H R$, Hazard ratio; $C I$, confidence interval; $C E$, Carpentier-Edwards. &
\end{tabular}


A

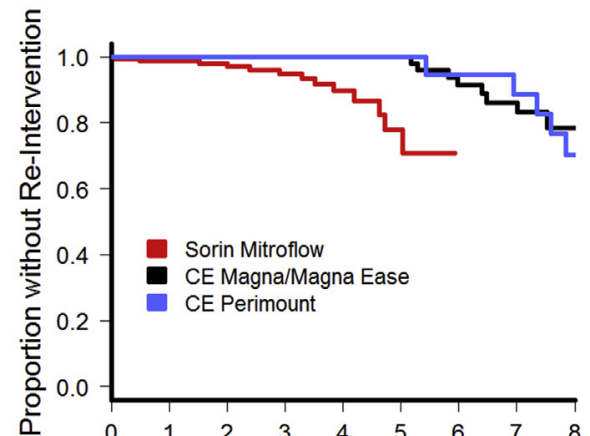

Time since Pulmonary Valve Replacement, yr

No. at Risk

$\begin{array}{lc}\text { Sorin } & 180 \\ \text { CE Magna } & 100 \\ \text { CE Perimount } & 27\end{array}$

90
67
19

11
52
18

1
18
14
B

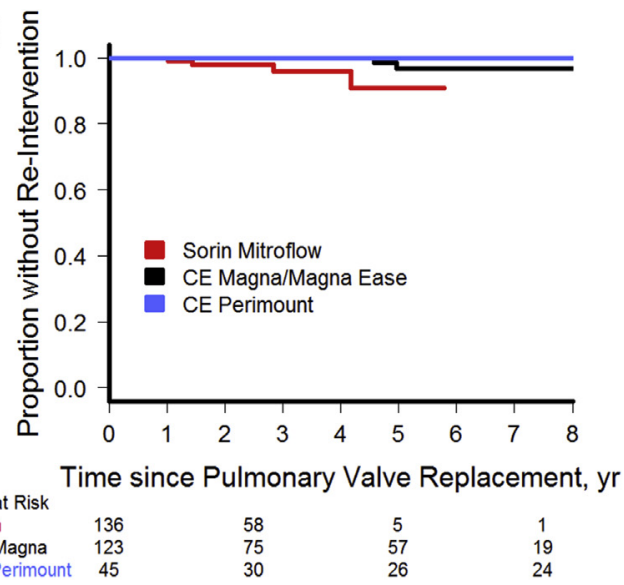

FIGURE 2. A, Freedom from reintervention by valve type in children, 32 events. Log-rank $P<.001$. Truncated at 8 years. Number of events not shown are 2 in the CE (Irvine, Calif) Magna/Magna Ease and 4 in the CE Perimount. See Table 2 for 95\% confidence limits for 3-, 5-, and 10-year event rates. B, Freedom from reintervention by valve type in adults, 9 events. Log-rank $P=.03$. Truncated at 17 years; 1 event in the CE Perimount group not shown. Truncated at 8 years; number of events not shown are 1 in the CE Magna/Magna Ease and 1 in the CE Perimount. See Table 2 for $95 \%$ confidence limits for 3-, 5-, and 10-year event rates. $C E$, Carpentier-Edwards.

significant in the model (ie, ignoring BMI $z$ score, which was calculable only for patients aged $<20$ years). The hazard of reintervention was approximately $10 \%$ lower for each increasing year of age at surgery (HR, 0.91; 95\% CI, $0.87-0.95 ; P<.001)$. The age-adjusted hazard of reintervention differed by valve type (Figure 1, $B$; Table E3; $P<.001)$. The Sorin Mitroflow valve was a significant age-adjusted risk factor for reintervention relative to the 2 other valve types (HRs both $>7$, all $P<.001$ ). There was no statistical difference between the CE Magna/MagnaEase and the $\mathrm{CE}$ Perimount valve types $(P=.35)$. The difference among valve types remained $(P=.007)$ after adjustment for era (before 2006 vs 2006 or later). Neither labeled valve size nor valve orifice area was significant when added to the ageadjusted model $(P \geq .8)$. As noted earlier, there was no significant interaction between age and valve type $(P=.61)$, indicating that the magnitude of the valve type differences is similar for younger and older patients, or alternatively that there is insufficient evidence to declare the differences according to valve type as significant (Figure 2, $A$ and $B$ ).

In a secondary analysis, we investigated the association of weight-for-age and BMI-for-age $z$ scores with time to reintervention in the patients who underwent initial surgery before age 20 years $(\mathrm{N}=328,27$ events). Patients with low BMI outside the normal range $(\mathrm{BMI}<-2)$ at the time of initial surgery were at significantly increased risk of reintervention, even after adjustment for age at surgery and valve type (adjusted HR, 5.9; 95\% CI, 2.0-17.2).

\section{DISCUSSION}

Historically, pulmonary and aortic homografts were the predominantly used replacement conduits for PVR. ${ }^{5}$ However, Caldarone and colleagues ${ }^{6}$ reported the development of valve dysfunction and subsequent pulmonary valve prosthesis failure in younger patients who received homograft implantation. This accelerated degradation was postulated to be due to enhanced immune mechanisms in younger patients, ${ }^{7-9}$ and thus alternative PVR options have been considered. The current study assessed reintervention after PVR with all bioprosthetic valve types in patients with CHD who were treated at Boston Children's Hospital between 1996 and 2014.

Because of the limited number of studies in patients with CHD with pulmonary valve disease, many of the decisions about what types of valves to use in the pulmonary position have relied on extrapolations from the aortic valve experience. We recently reported our experience with bioprosthetic valves in the aortic position in patients with CHD. Younger patients undergoing aortic valve replacement with the Sorin Mitroflow LXA pericardial valves without antimineralization treatment were found to be at significantly higher risk for rapid progression from mild to severe calcific aortic stenosis. ${ }^{10}$ These findings corroborated the findings in adult patients in whom calcification of bioprosthetic heart valve leaflets was a primary contributor to structural valve deterioration. ${ }^{11-13}$ However, in adult patients, recent studies show that improved design and antimineralization treatments in the more recent third-generation bioprosthetic valves lead to improved performance. ${ }^{14-18}$

Despite recent promising short- and mid-term results with bioprosthetic tissue valves for PVR, ${ }^{19-22}$ the longterm effects of calcium deposition remain problematic and require reintervention within 10 years. ${ }^{23,24}$ Valve rigidity due to leaflet calcification is a major mode of bioprosthetic valve failure, and calcium accumulation can be expected to allow decreased freedom from reintervention. Ultimately, these concerns led to the current 
review, analyzing the association between the valve type and reintervention and the potential impact that anticalcification treatments play in the pulmonary position in young patients. Although it may appear from our results that anticalcification treatments are beneficial, such as in the nontreated Sorin Mitroflow LXA valve, which had significantly higher age-adjusted reintervention rates relative to all other valve types (HRs all $>7$, all $P \leq .01$ ), it is also important to consider other factors contributing to valve failure, because not all nontreated valves failed. For example, the Sorin Mitroflow LXA and CE Perimount valves do not have anticalcification treatment, but the Sorin Mitroflow has a significantly shorter time to reintervention (HR, 25.9). Our 5 -year reintervention rate of $19 \%$ after placement of the Sorin Mitroflow LXA valve (median, 16.5 years) was corroborated by Schubert and colleagues, ${ }^{25}$ who reported an $18 \%$ reintervention rate at 5 years in 84 patients (median, 18.3 years), with a mean follow-up matching that of our cohort (2.4 years). On the basis of these findings, patients receiving the Mitroflow LXA valve warrant close follow-up.

Structural and functional characteristics of the bioprosthetic valve are fundamental for optimal performance after PVR. Bioprosthetic valves can be constructed of bovine, porcine, or pericardial tissue, with or without stents, and with various geometric properties. Four types of bioprosthetic valves, including the CE Perimount, CE Magna, Sorin Mitroflow, and CE porcine valves, were previously assessed in patients with TOF who received PVR at Boston Children's Hospital. ${ }^{21}$ In that analysis, a sharp decrease was demonstrated in the freedom from pulmonary valve reintervention after 5 years of follow-up, with $74 \%$ reintervention. The current study further examines patients undergoing PVR over a longer time period with a subset analysis. In this more comprehensive larger follow-up series, we have identified specific valve type and all measures related to younger patient age at surgery to be important predictors of reintervention. Of note, there was no significant interaction between age and valve type $(P=.61)$, indicating that the magnitude of the valve type differences is independent of age.

Time to reintervention differed significantly by age at surgery, with the risk of reintervention being 5 times greater for children than adults and decreasing by $10 \%$ for each increasing year of age at surgery. Almost all events occurred more than 3 years after the primary surgery, at which time the differences by age emerged. This suggests that clinical follow-up of patients should be carefully monitored on the basis of valve type and age after 3 years.

We hypothesized that valve size may be associated with reintervention independently of age. McKenzie and colleagues $^{22}$ reported that age less than 13 years at surgery $(P=.003)$ and smaller valve size $(P=.025)$ were independently associated with increased risk of valve reintervention. In the current series, we found in univariate analysis that a larger valve size was protective against reintervention with an HR of 0.76 per millimeter of labeled valve size. However, when instead examining valve orifice area indexed to BSA (essentially examining valve size while holding BSA constant), a larger valve size was a risk factor for reintervention, a finding similar to that of Chen and colleagues. ${ }^{21}$ They reported a reduced time to structural valve deterioration in patients with TOF with a larger BSAindexed valve area. However, in our series, neither larger valve size nor BSA-adjusted valve orifice size was a significant independent predictor of reintervention. Age at surgery, a strong correlate of the valve size used, was present in the multivariable model.

A novel finding in this analysis was that in patients aged less than 20 years and patients with a BMI more than 2 standard deviations below normal were 6 times more likely to experience valve failure in covariate-adjusted analysis. This finding is similar to that of Laux and colleagues, ${ }^{26}$ who identified low BMI as a risk factor for atrioventricular valve reoperation in 31 children with univentricular hearts, and Rossano and colleagues, ${ }^{27}$ who identified low BMI measured before transplant as an independent predictor of lower graft survival in 105 pediatric transplant recipients. Children with low BMI may merit closer monitoring after PVR or nutritional counseling to increase BMI before the scheduling of surgery.

\section{Study Limitations}

First, although these analyses use covariate adjustment, such adjustment may be imperfect with respect to correcting for differences in the youngest and oldest patient subgroups, that is, those who received the nontreated Sorin Mitroflow LXA and CE Perimount valves, because the number of patients who overlapped with similar ages was relatively small. Therefore, it is possible that differences in outcome rates by valve type may be smaller than estimated. Second, the threshold for reintervention after PVR may have changed during the time period of this study (1996-2014), and if so, valve-specific reintervention rates may not be fully comparable. Third, this analysis does not take into account repeated reinterventions per patient; it models only the time to first reintervention. Thirty cases had more than 1 reintervention during the period of follow-up, and if included may yield slightly higher statistical power to detect significant risk factors. Fourth, because of our practice of valve upsizing, our findings provide little information on outcomes with small valves relative to BSA. Last, because the period of follow-up for this analysis spanned approximately 3 decades, it is possible that other aspects of surgical technique have changed in that period and are not fully accounted for in our comparisons of time with PVR by valve type. In particular, our results may not be generalizable to the Sorin Mitroflow Phospholipid Reduction Treatment valve. 


\section{CONCLUSIONS}

Bioprosthetic PVR in patients with CHD has acceptable short-term outcomes, despite younger patients having more reinterventions. Independently of age, different valve types have different rates of reintervention. These differences in patient age and valve type may be important in valve selection and follow-up.

\section{Webcast}

You can watch a Webcast of this AATS meeting presentation by going to: http://webcast.aats.org/2015/Video/Tuesday/ 04-28-15_4E_0905_Nomoto.mp4.

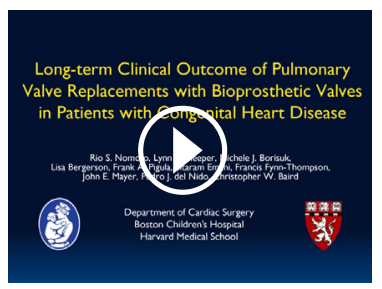

\section{Conflict of Interest Statement}

Authors have nothing to disclose with regard to commercial support.

\section{References}

1. Gengsakul A, Harris L, Bradley TJ, Webb GD, Williams WG, Siu SC, et al. The impact of pulmonary valve replacement after tetralogy of Fallot repair: a matched comparison. Eur J Cardiothorac Surg. 2007;32:462-8.

2. Warner KG, O'Brien PK, Rhodes J, Kaur A, Robinson DA, Payne DD. Expanding the indications for pulmonary valve replacement after repair of tetralogy of Fallot. Ann Thorac Surg. 2003;76:1066-71.

3. Flameng W, Rega F, Vercalsteren M, Herijgers P, Meuris B. Antimineralization treatment and patient-prosthesis mismatch are major determinants of the onset and incidence of structural valve degeneration in bioprosthetic heart valves. J Thorac Cardiovasc Surg. 2014;147:1219-24.

4. Zhang X, Loberiza FR, Klein JP, Zhang MJ. A SAS Macro for estimation of direct adjusted survival curves based on a stratified Cox regression model. Comput Methods Programs Biomed. 2007;88:95-111.

5. Zubairi R, Malik S, Jaquiss RD, Imamura M, Gossett J, Morrow WR. Risk factors for prosthesis failure in pulmonary valve replacement. Ann Thorac Surg. 2011;91:561-5.

6. Caldarone CA, McCrindle BW, Van Arsdell GS, Coles JG, Webb G, Freedom RM, et al. Independent factors associated with longevity of prosthetic pulmonary valves and valved conduits. J Thorac Cardiovasc Surg. 2000;120:1022-31.

7. Albert JD, Bishop DA, Fullerton DA, Campbell DN, Clarke DR. Conduit reconstruction of the right ventricular outflow tract: lessons learned in a twelve-year experience. J Thorac Cardiovasc Surg. 1993;106:228-36.

8. Baskett RJ, Ross DB, Nanton MA, Murphy DA. Factors in the early failure of cryopreserved homograft pulmonary valves in children: preserved immunogenicity? J Thorac Cardiovasc Surg. 1996;112:1170-9.

9. Rajani B, Mee RB, Ratliff NB. Evidence for rejection of homograft cardiac valves in infants. J Thorac Cardiovasc Surg. 1998;115:111-7.

10. Saleeb SF, Newburger JW, Geva T, Baird CW, Gauvreau K, Padera RF, et al. Accelerated degeneration of a bovine pericardial bioprosthetic aortic valve in children and young adults. Circulation. 2014;130:51-60.

11. Baskett RJ, Ross DB, Nanton MA, Murphy DA. Factors in the early failure of cryopreserved homograft pulmonary valves in children: preserved immunogenicity? J Thorac Cardiovasc Surg. 1996;112:1170-9.

12. Rajani B, Mee RB, Ratliff NB. Evidence for rejection of homograft cardiac valves in infants. J Thorac Cardiovasc Surg. 1998;115:111-7.
13. Zubairi R, Malik S, Jaquiss RD, Imamura M, Gossett J, Morrow WR. Risk factors for prosthesis failure in pulmonary valve replacement. Ann Thorac Surg. 201 1;91:561-5.

14. Grunkemeier GL, Li HH, Naftel DC, Starr A, Rahimtoola SH. Long-term performance of heart valve prostheses. Curr Probl Cardiol. 2000;25:73-154.

15. Chikwe J, Filsoufi F. Durability of tissue valves. Semin Thorac Cardovasc Surg. 2011;23:18-23.

16. Borger MA, Ivanov J, Armstrong S, Christie-Hrybinsky D, Feindel CM, David TE. Twenty-year results of the Hancock II bioprosthesis. J Heart Valve Dis. 2006; 15:49-55.

17. McClure RS, Narayanasamy N, Wiegerinck E, Lipsitz S, Maloney A, Byrne JG, et al. Late outcomes for aortic valve replacement with the Carpentier-Edwards pericardial bioprosthesis: up to 17-year follow-up in 1,000 patients. Ann Thorac Surg. 2010;89:1410-6.

18. Walley VM, Rubens FD, Campagna M, Pipe AL, Keon WJ. Patterns of failure in Hancock pericardial bioprostheses. J Thorac Cardiovasc Surg. 1991;102:187-94.

19. Lee C, Park CS, Lee CH, Kwak JG, Kim SJ, Shim WS, et al. Durability of bioprosthetic valves in the pulmonary position: long-term follow-up of 181 implants in patients with congenital heart disease. J Thorac Cardiovasc Surg. 2011;142:351-8.

20. Shinkawa T, Anagnostopoulos PV, Johnson NC, Watanabe N, Sapru A, Azakie A. Performance of bovine pericardial valves in the pulmonary position. Ann Thorac Surg. 2010;90:1295-300.

21. Chen PC, Sager MS, Zurakowski D, Pigula D, Baird CW, Mayer JE, et al. Younger age and valve oversizing are predictors of structural valve deterioration after pulmonary valve replacement in patients with tetralogy of Fallot. $J$ Thorac Cardiovasc Surg. 2012;143:352-60.

22. McKenzie ED, Khan MS, Dietzman TW, Guzmán-Pruneda FA, Samayoa AX, Liou A, et al. Surgical pulmonary valve replacement: a benchmark for outcomes comparisons. J Thorac Cardiovasc Surg. 2014;148:1450-3.

23. Butany J, Feng T, Luk A, Law K, Suri R, Nair V. Modes of failure in explanted Mitroflow pericardial valves. Ann Thorac Surg. 2011;92:1621-7.

24. Geva T. Indications for pulmonary valve replacement in repaired tetralogy of Fallot: the quest continues. Circulation. 2013;128:1855-7.

25. Schubert SA, Myers JL, Kunselman AR, Clark JB. Early outcomes of pulmonary valve replacement with the Mitroflow bovine pericardial bioprosthesis. Ann Thorac Surg. 2015;99:1692-9.

26. Laux D, Vernat M, Lambert V, Gouton M, Ly M, Peyre M, et al. Atrioventricular valve regurgitation in univentricular hearts: outcomes after repair. Interact Cardiovasc Thorac Surg. 2015;20:622-30.

27. Rossano JW, Grenier MA, Dreyer WJ, Kim JJ, Price JF, Jefferies JL, et al. Effect of body mass index on outcome in pediatric heart transplant patients. $J$ Heart Lung Transplant. 2007;26:718-23.

Key Words: congenital, pulmonary valve, replacement, bioprosthetic

\section{Discussion}

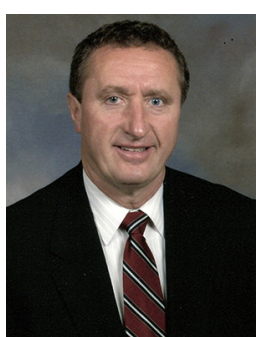

Dr J. Brown (Indianapolis, Ind). PVR is an extremely important topic for us to be discussing, particularly as it pertains to CHD and adults with CHD, in that the pulmonary valve, at least at our institution, is 5 times more in need of replacement than the aortic valve in children. Rio S. Nomoto, a third-year medical student at Tufts, and her colleagues from Boston have done a phenomenal job in analyzing and presenting a large series of patients requiring PVR whose mean age was 21 years; however, half of their patients were aged less than 18 years.

This analysis was done over 18 years. Seventy percent of the patients had the diagnosis of TOF, and $70 \%$ of the patients previously had a transannular patch. Pulmonary regurgitation was the primary indication for PVR in 
approximately $80 \%$ of their patients. Their early and late mortality was extremely low, at $3 \%$. And again, echocardiogram follow-up was available in approximately $70 \%$ of the patients receiving PVR. Echocardiogram evidence of structural valve dysfunction was present on echocardiogram in only $60 \%$ of their patients, with pulmonary stenosis being twice as common as pulmonary regurgitation for the definition of structural valve deterioration, and again, only 44 patients have required reintervention to date.

Three pericardial stented valves were compared with a small group of porcine valves. Children aged less than 18 years had a 5-fold higher incidence of reintervention than children aged more than 18 years. Some $100 \%$ of children aged less than 6 years were predicted to require PVR on a Kaplan-Meier curve, and in children aged less than 12 years, the need for PVR is predicted to be $75 \%$ at 10 years. Obviously, older children fared better.

Again, the only independent risk factor for reoperation was the valve type, with a Sorin Mitroflow (Milan, Italy) and untreated bovine pericardial valves having the greatest need for reintervention. The Sorin valve was the most common and the most recently used valve substitute, which they started using in 2006, and again, porcine valves were used in only 22 patients.

I have a few comments and questions. First, this was an excellent presentation and a well-written article that they provided for me to review. Their statistical analysis was extensive and exhaustive. This article confirms the statement that has been made over and over again that PVR remains a weak link in our management of CHD, particularly in children aged less than 12 years. Your article, like others, has demonstrated that the failure mode for pericardial valves is stenosis, being twice as common as regurgitation.

Our center has minimal experience with bovine pericardial valves in the pulmonary position, and we have favored biologic stentless valves in a series of more than 1200 patients over the past 30 years, because I guess we thought that the stentless valve had a bigger effective orifice area and appeared to be more durable than stented valves, at least in our experience.

How did you define prosthetic valve dysfunction or failure in your series? What was the gradient across the stentless valves at the time of reintervention?

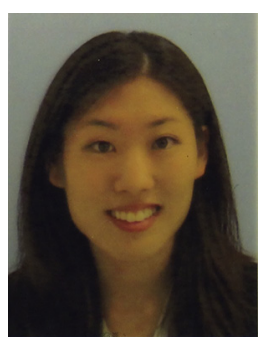

Rio S. Nomoto (Boston, Mass). It was difficult in this study of more than 600 patients to define structural valve deterioration and, more specifically, the onset of deterioration. Therefore, we defined valve failure as reintervention, which is the primary outcome measure of the study. However, we do think it is important to note that even when we looked at the latest echocardiogram obtained on each patient, only $16 \%$ had evidence of moderate or greater stenosis or regurgitation.
Dr Brown. What was the gradient across the valves? In the patients you had to reintervene in, what was the gradient that you use for the need for reintervention?

Rio S. Nomoto. I'm not sure exactly what the numbers are, the averages are, but the primary indication for reintervention was generally based on symptoms. Right ventricular outflow gradient and deterioration of the right ventricular function were also considered.

Dr Brown. Did you have a degree of pulmonary regurgitation that prompted you for reintervention? Did you use only echocardiography or magnetic resonance imaging (MRI) data comparing end-diastolic volumes as an indication for reoperation? Did you operate on asymptomatic patients who met a specific criteria?

Rio S. Nomoto. I think that would be different for each patient. So there would be cases in whom the echocardiogram would be more important than symptoms depending on the patient.

\section{Dr Moon. Chris?}

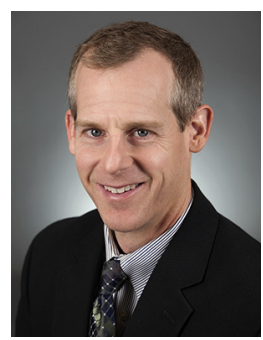

Dr C. Baird (Boston, Mass). Most of these patients also had MRI scans, and indexed ventricular volume also played an important role in that.

Dr Brown? Well, because this Sorin Mitroflow was your most common valve used and the most recent pulmonary valve substitute, are you still using the Sorin Mitroflow for PVR?

Rio S. Nomoto. We have stopped using the Sorin Mitroflow valves and are following up on these patients more closely.

Dr Brown. Currently, what is your valve replacement of choice, particularly for children aged less than 12 years?

Rio S. Nomoto. In the youngest infant patients, we continue to use homografts when needed. For younger children with a large enough annulus for a stented valve, we have tended to use stented porcine valves, although admittedly, we have not defined a specific age cutoff for using porcine valves. In older children and younger adults, we are implanting the Edwards Magna Ease valve (Carpentier-Edwards, Irvine, Calif). However, recently we have begun implanting more stentless porcine valves.

Dr Brown. Because TOF included your largest patient population for PVR, have your surgeons changed their management of the RVOT at the time of initial repair? Dr Baird may want to tackle that one.

Dr Baird. We have changed this over time, and now we tend to try to spare more valves, and obviously we are not doing as many transannular patches. Does that answer your question?

Dr Brown. It does. Do you have any idea of what your incidence of transannular patching is for tetralogy currently?

Dr Baird. Very low, probably less than $10 \%$. 
Dr Brown. Do you have a hypothesis as to why 1 of the nontreated pericardial valves had the highest degree of structural valve degeneration and another untreated pericardial valve had the lowest?

Rio S. Nomoto. We have tried answering this question, but we do not have a definite answer. What this does suggest is that there is likely more than a single factor, such as the lack of antimineralization treatments, involved in failure of these valves. Because both the CE Perimount valves and Magna valves (Irvine, Calif) have similar stent design, this might suggest that the stent plays an important role.

Dr Brown. Jeff Poynter, a Kirklin-Ashburn fellow, reported last year a multi-institutional series on PVRs in children aged less than 2 years and demonstrated that the bovine jugular valve had the best outcomes, at least in children aged less than 2 years. It turns out that the bovine jugular valve has been the valve replacement of choice at our place for the last 16 years. What is your experience thus far with the bovine jugular venous valve?

Rio S. Nomoto. We did not look at the bovine jugular vein valves and instead focused on the surgical reintervention in this study. However, we could in the future collaborate with the cardiologists to look at that data.

Dr Brown. I think what it points out is that this is an ongoing issue. We are still questing for a pulmonary valve that will last 20 years in a child or young adult, and we still don't have the answer. So we need a multi-institutional, much larger series of patients that will help us answer that question.

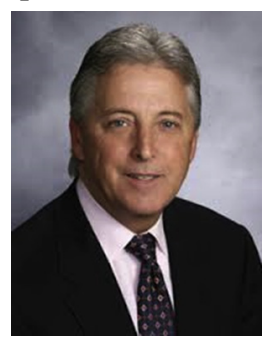

Dr E. Verrier (Seattle, Wash). Did you separate the age issue versus the size of the valve issue? So in many of these instances you can tailor a patch that will allow a certain size valve and therefore a different gradient, a different set of hemodynamics, and, at least certainly in comparison with the aortic position, a different outcome if you use a bigger valve. Over the years, have you seen a correlation between the size of that valve and its long-term durability and does that influence now how you approach these reoperations?

Dr Baird. That is an important question. Several years back, Dr Peter Chen published our experience, and what we found is that actually oversizing the valve led to increased structural valve deterioration. So we generally try not to oversize the valves.

Dr Verrier. The only question that comes up, it is a little bit to the Tirone David operation, is does it have an impact if you then are going to go back in the older adult to put a transcatheter valve in the pulmonary position and does that affect your decision on what size of valve to put in now?

Dr Baird. It does, and it is important to note that if you put in too large a valve it makes it difficult right now do a transcatheter valve without stacking stents in there. So a 23 or a 25 valve may be the ideal valve for that at this time.

Dr J. Forbess (Dallas, Tex). Wonderful presentation. Over time you were clearly operating on younger and younger patients, but when you looked at the outcomes, the reintervention rate is a lot higher, and I was curious, how many of those younger patients were largely asymptomatic or completely asymptomatic and you were operating on the basis on right ventricular dimension data derived from MRI and those thresholds were developed from distinctly older patient data sets?

This is a question that has been worrying me. When parents bring me an 11-year-old who is completely asymptomatic but has an RV that by MRI criteria that are out there and being used by our field, the patient meets criteria for a valve replacement, but I know that that valve is not going to last that long, should we be observing some of those patients until they are done with their teen years, for instance, and then putting the valve in?

Dr Baird. So, Joe, I think your question, summarized, is should we be operating on these children sooner or later, and fundamentally over the last several years we have tended to operate sooner before the ventricles become too dilated, thinking that ultimately we can put a transcatheter valve in these later, but we would try to preserve ventricular function early.

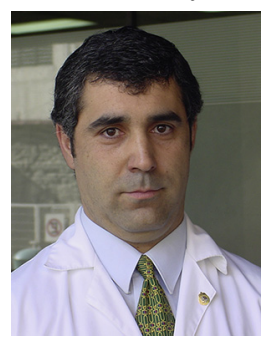

Dr P. Becker (Santiago, Chile). What is your current policy regarding anticoagulation or platelets antiaggregation, and has this policy evolved over time? Dr Baird. Generally we treat these patients with aspirin, which hasn't changed too much over time. 


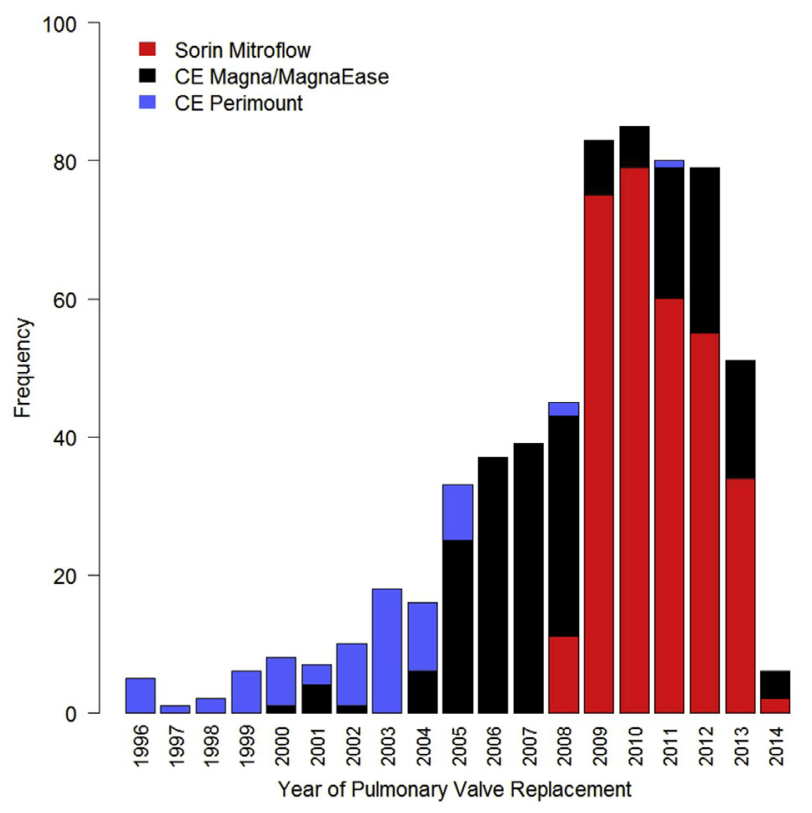

FIGURE E1. PVR by year $(\mathrm{N}=611)$. The year 2014 includes data for

2 months only. $C E$, Carpentier-Edwards.

TABLE E1. Rates of reintervention (surgical or catheter-based Melody [Medtronic Inc, Minneapolis, Minn] pulmonary valve placement) by age at surgery

\begin{tabular}{|c|c|c|c|c|c|}
\hline \multirow[b]{2}{*}{ Variable } & \multicolumn{5}{|c|}{ Age at PVR, y } \\
\hline & $<6$ & $6-<12$ & $12-<18$ & $18-<27$ & $\geq 27$ \\
\hline No. of patients & 56 & 98 & 153 & 148 & 156 \\
\hline \multicolumn{6}{|l|}{ Follow-up time, y } \\
\hline Mean \pm SD & $3.0 \pm 2.0$ & $3.3 \pm 2.9$ & $3.8 \pm 3.2$ & $3.6 \pm 3.5$ & $3.8 \pm 3.4$ \\
\hline Median (IQR) & $3.0(1.7-4.0)$ & $2.8(0.7-4.9)$ & $3.6(1.2-5.6)$ & $2.9(1.1-5.0)$ & $3.0(1.0-5.8)$ \\
\hline Number of events & 8 & 13 & 11 & 8 & 1 \\
\hline \multicolumn{6}{|c|}{ Event rates $(95 \% \mathrm{CI})^{*}$} \\
\hline 3-y event rate & $5.7 \%(1.4-21.2)$ & $2.9 \%(0.7-11.4)$ & $1.7 \%(0.4-6.5)$ & $3.2 \%(1.0-9.7)$ & $0 \%$ \\
\hline 5-y event rate & $15.1 \%(4.1-47.1)$ & $10.3 \%(4.3-13.6)$ & $5.1 \%(1.8-13.9)$ & $9.6 \%(4.2-21.1)$ & $0 \%$ \\
\hline 10 -y event rate & - & $67.7 \%(38.9-92.5)$ & $25.4 \%(10.1-55.6)$ & $9.6 \%(4.2-21.1)$ & $0 \%$ \\
\hline
\end{tabular}

$P V R$, Pulmonary valve replacement; $S D$, standard deviation; $I Q R$, interquartile range; $C I$, confidence interval. *Kaplan-Meier event rate estimates. 
TABLE E2. Univariate Cox regression analysis of time to reintervention

\begin{tabular}{|c|c|c|c|c|}
\hline Variable & $\mathbf{N}$ & Events & HR & $P$ value \\
\hline Age at surgery, $\mathrm{y}$ & 611 & 41 & $0.90(0.86-0.94)$ & $<.001$ \\
\hline Age $<18$ y at surgery & 611 & 41 & $4.85(2.23-10.64)$ & $<.001$ \\
\hline Age at surgery category, $y$ & 611 & 41 & & $<.001$ \\
\hline $12-<18$ vs $\geq 27$ & & & $11.41(1.47-88.58)$ & \\
\hline $12-<18$ vs $18-<27$ & & & $1.51(0.58-3.93)$ & \\
\hline $12-<18$ vs $6-<12$ y & & & $0.38(0.17-0.86)$ & \\
\hline $12-<18$ vs $<6$ & & & $0.20(0.08-0.53)$ & \\
\hline$\geq 27$ vs $18-<27$ & & & $0.13(0.02-1.09)$ & \\
\hline$\geq 27$ vs $6-<12$ & & & $0.03(0-0.26)$ & \\
\hline$\geq 27$ vs $<6$ & & & $0.02(0-0.15)$ & \\
\hline $18-<27$ vs $6-<12$ & & & $0.25(0.10-0.65)$ & \\
\hline $18-<27$ vs $<6$ & & & $0.13(0.05-0.40)$ & \\
\hline $6-<12$ vs $<6$ & & & $0.53(0.22-1.32)$ & \\
\hline Female vs male & 611 & 41 & $0.93(0.49-1.78)$ & .84 \\
\hline TOF & 611 & 41 & $0.59(0.32-1.10)$ & .10 \\
\hline Surgery year $\geq 2006$ vs before 2006 & 611 & 41 & $3.39(1.35-8.55)$ & .010 \\
\hline $\mathrm{BSA}, \mathrm{m}^{2}$ & 6111 & 41 & $0.17(0.09,0.33=4)$ & $<.001$ \\
\hline Weight at surgery, $\mathrm{kg}$ & 611 & 41 & $0.96(0.95-0.98)$ & $<.001$ \\
\hline Weight-for age $z$ score (if $<20 \mathrm{y}$ ) & 353 & 34 & $0.83(0.68-1.01)$ & .07 \\
\hline Weight-for-age percentile (if $<20$ y) & 353 & 34 & $0.98(0.97-1.00)$ & .009 \\
\hline Weight-for-age $z$ score $<-2$ & 353 & 34 & $2.09(0.85-5.17)$ & .11 \\
\hline Weight-for-age $z$ score $>1$ & 353 & 34 & $0.21(0.03-1.53)$ & .12 \\
\hline BMI, $\mathrm{kg} / \mathrm{m}^{2}$ & 578 & 33 & $0.87(0.81-0.95)$ & $<.001$ \\
\hline BMI-for-age z-score (if $<20$ y) & 328 & 27 & $0.73(0.55-0.97)$ & .03 \\
\hline BMI-for-age percentile & 328 & 27 & $0.99(0.98-1.00)$ & .12 \\
\hline BMI-for-age $\mathrm{z}$ score $<-2$ & 328 & 27 & $4.42(1.64-11.93)$ & .003 \\
\hline BMI-for-age z score $>1$ & 328 & 27 & $0.94(0.38-2.36)$ & .90 \\
\hline Valve type & 611 & 41 & & $<.001$ \\
\hline Sorin Mitroflow (Milan, Italy) vs CE Magna/MagnaEase (Irvine, Calif) & & & $10.63(3.68-32.7)$ & \\
\hline Sorin Mitroflow vs CE Perimount & & & $21.90(5.47-87.66)$ & \\
\hline CE Magna/MagnaEase vs CE Perimount & & & $2.06(0.73-5.79)$ & \\
\hline Native outflow tract used & 600 & 35 & $0.37(0.18-0.77)$ & .007 \\
\hline Insertion method & 607 & 41 & & .58 \\
\hline PVR with anterior patch vs Isolated PVR & & & $1.82(0.56-5.98)$ & \\
\hline PVR with anterior patch vs PV with tube & & & $0.89(0.35-2.32)$ & \\
\hline Isolated PVR vs PV with tube & & & $0.49(0.12-2.06)$ & \\
\hline Labeled valve size, $\mathrm{mm}$ & 611 & 41 & $0.76(0.68-0.85)$ & $<.001$ \\
\hline Internal diameter valve size, $\mathrm{mm}$ & 611 & 41 & $0.73(0.66-0.82)$ & $<.001$ \\
\hline Valve orifice area (per $20 \mathrm{~mm}^{2}$ increase) & 611 & 41 & $0.84(0.78-0.89)$ & $<.001$ \\
\hline Valve orifice area/BSA, $\mathrm{mm}^{2} / \mathrm{m}^{2}$ (per $20 \mathrm{~mm}^{2} / \mathrm{m}^{2}$ increase) & 611 & 41 & $1.06(1.00-1.013)$ & .03 \\
\hline Surgical procedure concurrent with primary surgery & 611 & 41 & $1.14(0.61-2.11)$ & 69 \\
\hline Left pulmonary arterioplasty concurrent with primary surgery & 611 & 41 & $0.77(0.23-2.52)$ & .66 \\
\hline Left, right, or main pulmonary arterioplasty concurrent w/primary surgery & 611 & 41 & $1.67(0.76-3.68)$ & .20 \\
\hline
\end{tabular}

$H R$, Hazard ratio; $T O F$, tetralogy of Fallot; $B S A$, body surface area; $B M I$, body mass index; $C E$, Carpentier-Edwards; $P V R$, pulmonary valve replacement; $P V$, pulmonary valve. 
TABLE E3. Age-adjusted rates of reintervention (surgical or catheter-based Melody pulmonary valve placement) by valve type

\begin{tabular}{|c|c|c|c|}
\hline Variable & $\begin{array}{l}\text { Sorin Mitroflow } \\
\quad(\mathbf{N}=\mathbf{3 1 6})\end{array}$ & $\begin{array}{c}\text { CE Magna/ } \\
\text { Magna Ease } \\
(\mathrm{N}=\mathbf{2 2 3})\end{array}$ & $\begin{array}{c}\text { CE Perimount } \\
(\mathbf{N}=72) \\
\end{array}$ \\
\hline No. of patients & 316 & 223 & 72 \\
\hline No. of events & 17 & 13 & 11 \\
\hline \multicolumn{4}{|c|}{ Age-adjusted event rates $(95 \% \mathrm{CI})^{*}$} \\
\hline 3-y event rate & $3.8 \%(1.3-6.2)$ & $0 \%$ & $0 \%$ \\
\hline 5-y event rate & $13.4 \%(5.6-20.5)$ & $2.1 \%(0-4.9)$ & $0 \%$ \\
\hline 10 -y event rate & - & $25.2 \%(7.6-39.3)$ & $21.1 \%(5.8-34.0)$ \\
\hline
\end{tabular}

